\title{
REFLEXIONES SOBRE LA LECTURA
}

María Amoretti $H$.

\begin{abstract}
Modern literary analys is theories place special emphasis on the reader. This article gathers and synthesizes some of the features that allow for a definition of reading within the framework of present society.
\end{abstract}

Pocas veces me he encontrado con un tema tan asediado como éste por esquemas recibidos, frases hechas, ideas preconcebidas y, sobre todo, mucha especulación.

En medio de tanta confusión he llegado a concluir que el problema fundamental con el tema está en que quienes lo abordan generalmente repiten los panegíricos de un discurso tan imperecedero como el de Magón y, por tanto, cometen el delito pragmático de ignorar el contexto y su receptor.

Quizá sea este delito pragmático una de las razones por las cuales no hayamos logrado interesar a las nuevas generaciones por la lectura, quizá sea esa una de las razones por las cuales las nuevas generaciones no reconozcan en el discurso sobre la lectura elementos de relación con el mundo en que viven y su forma de vida.

La actividad de la lectura depende de la época y del tipo de sociedad considerado, por tanto, las presentes reflexiones constituyen un esfuerzo por considerar el significado de la lectura en la época actual.

¿Qué significa leer hoy, en nuestra sociedad? Esta sería la pregunta inaugural de nuestras reflexiones.

Comencemos con el típico gesto inicial del filólogo, veamos lo que ha sido registrado como significado en el diccionario. ${ }^{1}$

Leer:

Pasar la vista por lo escrito o impreso, baciéndose cargo del valor y significación de los caracteres empleados, pronúnciense o no las palabras representadas por esos caracteres.

También dice:

Entender o interpretar un texto de este o de otro modo.

Y algo más:

Penetrar en el interior de uno por lo que exteriormente aparece, o venir en conocimiento de una cosa oculta que le baya sucedido.

La primera acepción relaciona el acto de leer con un objeto, el texto impreso. La segunda pasa de la simple relación, significante-significado, a la categoría de la interpretación, del entendimiento necesario para consecuentemente explicarlo y de paso señala que se puede entender de diversos modos. La última enfoca más bien el leer como el paso al interior por intermedio de caracteres externos, leer es una revelación, es hacer aparecer la cosa oculta.

¿Cuál de todas estas acepciones es la que la sociedad de hoy acepta en la práctica? Ninguna de ellas exactamente, pero tal vez la tercera si se le imprimen ciertos matices.

Creo que el uso de la palabra lector nos da algunas pistas. Oímos decir lector electromagnético, lectora óptica y hasta el mismo diccionario de la Real Academia registra en su última edición, el aparato que hace pasar los microfilmes, como una de las acepciones del término 
lector, y hay una canción de rock que se titula "lee mi cuerpo". Estos hechos de lenguaje son los síntomas de que un cambio se está operando en el concepto de lectura. Lo legible hoy no es únicamente el texto impreso o los signos lingüísticos, sino todo aquello que se presente como signo o simplemente como síntoma. Leer parece acercarse más o descifrar, descodificar.

Las causas de este cambio están sobre todo en la aparición de esa ciencia nueva llamada semiótica que se hizo cargo del estudio de todos los sistemas significantes. Su influencia ha sido tal en el pensamiento de nuestra época que ha variado incluso la percepción de la realidad y sobre todo de la realidad social, a la cual ha llegado a traducir en términos de un intercambio simbólico y la ha redefinido como un espacio semiótico. Nuestra relación con la realidad incluso aparece mediatizada por una energía significante que, si bien tiene su máximo exponente en el lenguaje, se ha extendido a cuanto nos rodea, todo habla, todo tiene un lenguaje, todo busca un significado, porque el hombre no puede vivir sin el sentido y cuando le falta, amenaza con suicidarse.

Pues bien, si todo significa, todo puede ser susceptible de una lectura. Esto implica que el libro ya no es el único objeto de lectura y emerge un nuevo concepto para identificar todo aquello que es legible: el texto. A pesar de que este término se ha constituido en un vade me cum que transita en los diversos campos del saber, quien mejor lo ha definido ha sido Roland Barthes ${ }^{2}$. Este autor comienza por distinguir entre obra y texto y de sus palabras se deriva fácilmente que bajo el término de obra está hablando del libro. La obra, dice Barthes es un fragmento de sustancia, ocupa un lugar en el espacio, se ve, se sostiene en la mano; mientras que el texto es un campo metodológico, se experimenta en un trabajo, una producción, su movimiento constitutivo es la travesía, su lógica es metonímica, la lógica de las asociaciones, de las contigüidades, de las acumulaciones y coincide con una liberación de la energía simbólica para realizar el plural mismo del sentido, un plural irreductible; por eso la metáfora del texto es la de la red; si el texto se amplía es por efecto de una combinatoria, de una sistemática. Después de leer esto podría quedar la impresión de que Barthes devalúa el concepto de libro, pero creo que lo que hace es más bien devolverle su esencialidad. El libro fue siempre eso, el texto. Pero cuando se encerró su esencia, el lenguaje, en la materialidad de un puñado de hojas y Gutemberg lo convirtió en el viajero de todos los caminos, su materialidad terminó por hacer olvidar su alma. Lo que hace Barthes es recuperar el sentido del libro, es decir, recordar a todos su finalidad, poner el pensamiento en movimiento, liberar energías. La mecánica del libro, ese movimiento llamado texto, es factible de aplicarse a otros objetos que no tienen la forma del libro pero que han sido impregnados de esa misma energía que antes se creía sólo era constitutiva del libro, propia del libro, la energía del lenguaje.

Efectivamente, antes se creía que el lenguaje solamente se hablaba o se leía en el impreso y nada más, no había otras fuentes; lo que no era lenguaje, las otras realidades, estaban separadas y su única relación con él era la relación de las denominaciones. Pero de pronto se revela que el lenguaje hacía algo más con ellas: les transfería su energía estructurándolas a su imagen y semejanza, él que es la estructura de las estructuras, las ordenaba, las agrupaba, las jerarquizaba y al hacer esto les daba un valor del que carecían. A partir de ese momento, se toma conciencia de que si las cosas no valen por sí sino por el valor concebido por el lenguaje, entonces cuando las cosas se intercambian el intercambio se hace en nombre de ese valor. Prueba patente de ello es la publicidad en nuestros días, ella mejor que nadie conoce esa verdad y la explota y nosotros compramos o vendemos no las cosas en sí sino su valor simbólico, valor que la publicidad cuidadosamente manipula y transfiere a través de sus sutiles mecanismos. Luego se descubre que existía desde tiempos inmemoriales una práctica en el hombre cuya única finalidad era la de imitar este comportamiento del lenguaje, pero imitación como el juego en los niños, no se tomaban las cosas mismas sino las palabras, es decir el valor conferido a ellas por lenguaje y se procedía con las palabras de la misma forma que el lenguaje hacía con las cosas: se les daba un lugar, se las ordenaba, se las asociaba, se las agrupaba, en fin se les otorgaba valores nuevos. Y como esta práctica era para armar signos nuevos, valores nuevos, era entonces una práctica significante y se le ha conocido comúnmente como literatura. 
Pero si bien la literatura es la práctica significante que imita con mayor cercanía al lenguaje, hay otras más aunque, a mi juicio, derivadas de ella. Volviendo al texto. Si todas las cosas están impregnadas de lenguaje y el valor de cambio, por el que se trasiegan, es el que el lenguaje les ha otorgado, para saber lo que valen, lo que significan es necesario aprehender el lugar que ocupan, las contigüidades que las cercan, las oposiciones que las complementan, en fin, hay que aprehenderlas como texto, es decir, hay que leerlas.

Vivimos entonces en la cultura del texto, o podríamos decir en un texto, en el texto de la cultura en el que para sobrevivir hay que saber leer. Me pregunto ahora si ¿no será esto un modo de conjurar la llamada cultura libresca?, ¿una forma de leer el libro integrando los saberes, viviéndolos como una unidad en nuestra vida cotidiana? En cada momento de nuestra vida lo que se nos presenta es un texto, cuando nos hablan nuestros padres colocan las palabras propias de los padres en un orden que les es propio, un orden al que ahora llaman discurso (modos de composición y combinación de las palabras caracterizados por grupos sociales de edad, de sexo, de profesión, de posición en el conjunto social), y no puedo leerlas si no parto del valor que ese discurso les confiere. Pero no se trata sólo de palabras, insisto; observamos la ciudad, la disposición de sus calles, la forma de los edificios, el color de los muros, los árboles seleccionados para su ornato y hablan porque tienen un valor concebido por el conjunto y cada elemento del conjunto define el propio de acuerdo con el valor del conjunto. La quiromancia, pienso ahora, intuyó bien esto de alguna forma, pues sus practicantes siempre afirmaron que las cartas hablaban y hablaban según la posición en que los movimientos del azar las colocaban. Los gestos hablan, los colores hablan, los cuerpos hablan y hasta la situación en la que me dispongo hablar habla y confiere un valor previo a lo que yo voy a decir. Todo habla aunque no se hable. Lo que hemos aprendido del lenguaje, lo que él nos ha enseñado es una forma de percepción que no está supeditada a los sentidos y logra penetrar alli donde ellos no logran llegar, por eso la textualidad no es sustancial, es la forma de lo sustancial, es lo intelectual, es más que percibir, conocer.
Si todo es legible es porque todo es susceptible de ser signo, de ser significante. Pero no todo significa en la misma forma. Se puede decir que hay grados en la significación. Leer una imagen en un texto televisivo no es lo mismo que leer una imagen en un texto literario; en aquel la imagen está ya elaborada, precisada; en éste la imagen debe ser elaborada por el lector. Aquella es sensorialmente perceptible; ésta es sólo imaginativamente sostenible.

Por esta diferencia, que es una diferencia de costo, esfuerzo, inversión, en la lectura, algunos explican la fácil inclinación del público por la televisión y el cada vez menor interés por la lectura del impreso. Si esto es así, entonces es posible pensar que la razón de la preferencia se debe a la ley del menor esfuerzo; es más cómodo leer una imagen ya elaborada que leer para poder elaborarla. Pero entonces me pregunto cómo este mismo principio de economía no se aplica en otras cosas. Todos estarán de acuerdo en que hoy por el culto al cuerpo, no sólo se paga cualquier cosa, sino que además se hacen grandes esfuerzos físicos y mentales, se condiciona la mente a aborrecer la comida, se sueldan las mandíbulas y se corre aunque para ello haya que dormir menos o arriesgar la vida en las carreteras. Me viene a la mente el famoso precepto helénico de "mente sana en cuerpo sano". Parece estar claro qué es mantener el cuerpo sano, pero la mente... tengo mis dudas. La salud mental, dicen algunos, se remedia en la recreación y en evitar los malos pensamientos. Pero no entiendo porqué la frase "mantener en forma" se aplica al cuerpo y no a la mente. ¿Cómo se digiere esto si además le agrego una idea que es de todos aceptada con gran convicción: la idea de que la mente, inteligencia o conciencia, es aquello que nos resulta, a nosotros, los seres humanos, como lo más distintivo y nos coloca en la cúspide de la jerarquía del reino animal? Si eso es una convicción, ¿por qué ese descuido con la mente, con el intelecto, en nuestros días? A pocos parece importarle mantenerlo en forma y nadie se cuida de la obesidad o debilidad de éste. Adiciono otra idea para confundirme más. Si las imágenes del hombre del futuro que se han puesto a circular a través de la ciencia ficción, especialmente, nos lo dibujan con una cabeza abultada por el crecimiento de su cerebro y el extraordinario 
desarrollo de su mente, ¿cómo es posible entonces que este hombre del siglo XXI que ya casi somos, antecedente de aquel, logre alcanzar la evolución intelectual sugerida por la imagen del hombre del futuro, si los hombres de hoy mantienen una actitud de total indiferencia por el desarrollo de sus funciones intelectivas?

Así como existe la gimnasia corporal, hay gimnasia para las mentes. La lectura es una gimnasia necesaria para mantener la mente en forma dentro de una cultura del texto.

$Y$ sin menospreciar otros objetos de lectura, me atrevo finalmente a lanzar una afirmación contundente para abrir la brecha y generar tensiones, afirmo que el mayor rendimiento se alcanza en el ejercicio de la lectura del texto literario y lo afirmo por que con ella se imita el poder significante del lenguaje, creando a partir de él otro lenguaje (la connotación, lo llaman algunos).

Una de las razones que tengo para pensar en la lectura de textos literarios como la lectura por antonomasia, se encuentra en el hecho de que este tipo de texto no está anclado a la realidad, que sus objetos de comunicación no son reales, sino ficticios, de modo que la convencionalidad del signo queda suspendida, la convencionalidad que garantizaba un cierto grado de precisión -lo que los expertos llaman referencialidad- queda suspendida (aunque no ignorada), para entrar en el territorio de la ambigüedad. Al suspender esa convencionalidad las palabras entran en una especie de delirio pues ya no refieren a lo que normalmente apuntaban, poniéndose de esta forma a prueba su valor usual. Esto significa que en el territorio de la ambigüedad nos vemos obligados a cambiar de punto de vista, a violentar nuestro consuetudinario esquema de percepción y exploramos el mundo del lenguaje como si lo encontráramos por primera vez y explorándolo descubrimos cosas, vetas insospechadas que a partir de ese momento comenzamos a explotar. Ajustar nuestros sentidos a un modo de percepción inédito, no es tarea fácil. El primer reto será el de comprender que en el texto literario los signos no son verdaderos significantes que remiten a significados, sino tan sólo instrucciones, solicitudes para la producción de nuevos signos. O sea, que es una actividad simbólica de segundo grado, pues lo que hacemos es repetir el gesto del lenguaje haciendo a las palabras lo que ya estas habían hecho a las cosas: otorgarles un concepto, darles un lugar, relacionarlas con otras, agruparlas. Todo, como en el momento de la creación del mundo.

Si es cierto que la Biblia, ese texto sagrado, resume las verdades que debe conocer el hombre, entonces el lenguaje es la verdad primera. Pues primero fue el Verbo, Dios, el Verbo Divino, y después fue todo lo demás, incluido el hombre. El lenguaje está primero en Dios y luego, por voluntad de Este, pasa al dominio del hombre. Por eso Dios, después de haber terminado la creación la llevó hasta el hombre para que éste le pusiera nombre a cada una de las cosas creadas. Es vital retener aquí que el lenguaje en Dios es entonces esencia y la creación, un acto performativo. Dios dijo hágase la luz y ésta fue hecha. En el hombre es tan sólo una categoría, el hombre no puede repetir ese acto performativo aunque el don del lenguaje le haya sido conferido. Sin embargo, el hombre no se resigna a ello y se pasa la vida imitando el poder creador de Dios. En la historia de la humanidad ha habido tal conciencia de este poder creador de la palabra, de su performatividad, que el hombre no ha dudado en otorgarle un poder mágico o sobrenatural.

La literatura es uno de los mejores actos miméticos del hombre, el que más lo acerca al gesto creador divino, pues es el intento de crear con la simple enunciación de las palabras.

Recuerdo ahora un texto literario que reflexiona, lo expresaría mejor si dijera se flexiona sobre sí mismo, y habla sobre su propio modo de construirse, un libro de Rafael Angel Herra. En este texto se habla del juego del crucigrama y del modo cómo las palabras, a las que se ordena de un modo singular, se sirven extrañamente unas a otras, "entrelazándose y transpirándose como amantes que se aman el uno al otro con muchos brazos y muchas piernas... Un verbo desciende en abismal caída, hasta abrir cavidades sin nombre. El alfabeto se apretuja, se explaya, dice y grita con ecos de carne en todas direcciones... acomodándose entre los cuadros ansiosos de simetría, en estratos y en columnas, donde se forjan espejos romboidales y laberintos en los cuales nacen los deseos ${ }^{\prime \prime}$.

Si la afición a los crucigramas forma y divierte, yo no tengo ningún pudor en aceptar que de los ejercicios de lectura derivo placer. 
Pero para dominar un juego es necesario saber cómo funciona y cuáles son sus reglas y me temo que muchos no juegan este juego porque lo desconocen, porque no saben jugarlo, nadie les ha enseñado cómo jugarlo.

Aprendámoslo haciéndolo:

Un sujeto llamado autor ha seleccionado ciertos elementos de la realidad (en forma de palabras) y los ordena bajo una cierta composición llamada texto. Al hacerlo ha alterado el orden que esos elementos tenían en la realidad y por lo tanto ha alterado simultáneamente su valor, los pone a nuestra disposición y nos invita a resolver la incógnita de ese nuevo valor. La función del autor es la del polo artístico y la del lector es la del polo estético. Es decir, la función de aquel es la de crear el texto y la función del lector es la de concretarlo. El fenómeno literario entonces es más que el texto, porque siendo éste tan sólo un conjunto de posibilidades de resolución, una pura virtualidad, necesita del lector para ser concretado; y es más que su lectura o concreción porque ella depende de las disposiciones del texto.

Leemos: "La casita es un enjambre". Por dónde empiezo. Selecciono "enjambre", me parece un tema, una pista que debo seguir. En primer plano distingo el elemento seleccionado, enjambre, y en el plano de fondo, su contexto. ¿De dónde lo sacó el texto? Esto es necesario saberlo para determinar su valor y luego evaluar la transformación de ese valor. Ojo que la palabra sola no es suficiente, es necesario su contexto, la especie de paquete en relación con el cual tiene un valor. Defino el contexto: ciencias naturales, la vida de las abejas; el enjambre se da cuando las abejas emigran en busca de otra casa. Ahora recuerdo que "casa" es precisamente la otra palabra seleccionada por el texto, pero yo la deseché. Entonces me devuelvo; dentro de ese conjunto, casa tiene el valor de colmena, vuelvo al punto de mi selección primera, enjambre, tengo un problema, hay algo que no calza, la casa no puede ser un enjambre según su valor en el contexto de las abejas; resuelvo: si el enjambre es el cambio o mudanza de colmena-casa, lo que debo retener es simplemente el valor de transformación o cambio.

Inmediatamente el texto se pone a describir esa casa; no es cualquier casa, por eso se esmera en describirla: enjalbegadas de cal sus chatas paredes, etc. La casa seleccionada es una casa de campo, la típica casa de adobes y en ella se ha destacado el bullicio y el movimiento de mucha gente que trabaja. Vuelvo a enjambre, es mi tema, la pista que he decidido seguir, y corrijo, enjambre será sobre todo el valor bullicio y movimiento, puesto que aquí, nadie se está cambiando de casa (por lo pronto). Pero el contexto, el plano de fondo de la palabra enjambre sigue funcionando y me sugiere ahora otros valores. Repaso el paquete con más detalle: abeja, colmena, enjambre, obreras, reina, zánganos, miel. Pero me doy cuenta de que ese mismo paquete es un texto donde los elementos también provienen de otro contexto y sólo por él adquieren su valor, pienso en obreras y reina, esos términos que se han usado para describir la vida de las abejas provienen de la organización social y sin embargo fueron incorporados en un paquete descriptivo que es de las ciencias naturales. Este paquete tiene un valor especial en la realidad extratextual donde es ya polivalente; funciona para describir una vida animal como para describir la vida en sociedad de los hombres; obreras remite al trabajo y al concepto de producción y, todavía más, a la división del trabajo. Tengo la tentación de saber si de la abeja obrera salió la nominación del trabajador obrero o si fue a la inversa, de paso recuerdo que el momento en que el texto se produjo es justamente aquel en que los que en otro paquete de palabras se habian denominado proletarios, decidieron identificarse con el nombre de obreros; en Costa Rica esta es la época de los movimientos obreros, pero me detengo, lo dejaré para otro día cualquiera, por lo pronto esa información no me es necesaria. Vuelvo al texto, entonces enjambre insiste en prolongar sus efectos y ha generado cambios en los valores de las frases siguientes: se trata del bullicio y del movimiento generado en el trabajo, en la producción.

La descripción de la casita de campo, ahora me doy cuenta, tiene una modificación, voy tras la pista. Conozco el esquema distributivo y los tópicos propios de esta imagen, en el corredor de la casa lo esperable son unas bancas, unas matas y tal vez sus flores; pero en este corredor lo que hay es una máquina y los que trabajan se dedican a faenas diferentes 
pero todas, eso sí, etapas de un mismo proceso, la producción del café. Resumo: división del trabajo, presencia de la máquina, en el escenario de una casita de adobe que proviene de un contexto de pintura idílica de los campos.

Vuelvo a sintetizar: advenimiento de la agroindustria; razono sobre la palabra advenimiento, el proceso agroindustrial tiene ya sus marcas distintivas en el escenario del texto, pero es incipiente porque el escenario en que está da la impresión de improvisado: la sala y el corredor de una casa. He disminuido mis tensiones y las de los signos en el texto, tengo una totalidad que parece integrar todos los elementos y he explicitado lo que el texto decía sin expresarlo. Pero no, hay más. La casa, pertenece a un contexto que le da el valor de intimidad; pero ahora que digo intimidad salta la palabra privacidad y entonces casa puede pertenecer a otro contexto más, el de la propiedad, el del dominio. Debo decidir. Por lo pronto me quedo con intimidad, un valor que de inmediato entra en conflicto con la imagen que me había forjado del advenimiento de la agroindustria, ya que este valor se relaciona con el mercado, el comercio, no con la intimidad. Cuando digo mercado, comercio, recuerdo el título, La Propia y me doy cuenta de que no tengo tal totalidad, pues no hay cierre; tengo una grieta porque intimidad funciona por negación y la cuestión de la propiedad sigue asediando. ¿Acepto su funcionalidad?, me pregunto. Qué tal si vuelvo al término privacidad y lo pego con el de propiedad, propiedad privada, pero ya me temo que abuso. Tengo una apertura de nuevo y nuevas tensiones. No es lo propio, es la propia, femenino, bueno, al menos concuerda en género y número con el término propiedad. Paso al siguiente párrafo.

Un grupo de mujeres, las escogedoras. Notorio, todas feas, constituyen un verdadero inventario de fealdades y todas comparten una misma larga mesa. En mesa aparte, otra mujer. Notorio: el resumen de todas las gracias. Me devuelvo para recoger los nuevos elementos y efectuar otra síntesis. El grupos de escogedoras, repertorio de fealdades, funciona como contraste para intensificar la figura de esa otra mujer, la bella. El texto prosigue ahora dándome el detalle de esta figura a través de un collage hecho con objetos vegetales: maíz, guiscoyol, guayacán, pitahaya. La cadena de descriptores se cierra con el señalamiento de que todos los elementos descritos: dientes, labios, carne, etc, son signos externos de un interior de pasiones ardorosas que se asoma por los ojos, se sale por la nariz y brinca en el pecho. Los movimientos de ese contenido de "pasiones ardorosas" son animales, pues saltan como cabra, "cabrillean" en las húmedas pupilas.

El párrafo concluye con el nombre de esta mujer y su correspondiente epíteto: "Es María Engracia, la guaria de Escazú".

María es el nombre de la fémina por excelencia, pienso, por eso casi todas las mujeres se llaman María. El modelo es el de la virgen María, cuyo mejor epíteto es "la llena de gracia". Tengo la tentación de pensar en Amado Nervo, pero mejor no. Maria Engracia, la relación es clara, el modelo de fémina, femenino. Recuerdo el título en femenino, La Propia. Pero el modelo está invertido, pues las gracias de esta María son exactamente el polo opuesto de las de la Virgen, son gracias terrenales, pasionales, nada celestiales, nada angelicales. Por otra parte, el texto compara la belleza de María Engracia con una flor, la guaria. Leo la correspondencia dentro del esquema mariano. La virgen es azucena, blancura, pureza. La guaria es morada (muerte, luto) y es la flor de una parásita (aunque ahora los entendidos dicen que no, en el imaginario popular se piensan y se nombran como parásitas, y esto es lo que cuenta, el valor en uso) cuya vida se alimenta de la muerte de otros, flor de la pudredumbre, encierra ella misma el contraste entre belleza y corrupción. Retengo para María Engracia el valor de corrupción. Pero, ¿cómo relaciono esta parte del texto con lo que tengo leído más arriba? Advenimiento de la agroindustria transformando el paisaje de la casita. Vuelvo a enjambre y comprendo que su valor como cambio y transformación sigue rigiendo y que la transformación no es positiva si considero el valor "corrupción" que acabo de forjar, que la transformación se vislumbra en el plano de la moral y, por lo tanto, es una degeneración. La belleza de María Engracia es una belleza pérfida, encuadrada como está dentro del esquema mariano. La belleza de la Virgen María es precisamente el reflejo de su belleza espiritual. En María Engracia, en cambio, la belleza miente porque no corresponde con lo que hay en su interior: un palpitar de pasiones ardorosas, que 
se manifiestan con movimientos de animal. La belleza de María Engracia es una provocación. Si coloco esta funcionalidad dentro del esquema mariano, encuentro otra modificación. María, la purísima, aplastará la cabeza de la provocación, la serpiente del paraíso. María Engracia encarna la provocación misma, es la invitación al pecado, a la caída, a la pérdida del equilibrio establecido en medio del paisaje idílico, paradisíaco, al que evoca el tópico de la casita de campo.

Lo que acabo de hacer no sólo es una síntesis de lo leído sino una proyección del futuro, pues lo que llevo leído además de condicionar lo que leo ahora, determina también lo que leeré después y lo que leeré después modificará, a su vez, lo que llevo leído. Descubro que tengo un punto de vista móvil y me doy cuenta del transcurso del tiempo, tomo conciencia de que el texto es un presente vivido por mí y por lo tanto estoy viviendo, en ese curso temporal, un evento. Si doy una mirada a la forma en que he transcrito mi experiencia de lectura, advierto que tiene la forma de una narración y en nada difiere de una narración deportiva que da cuenta de los movimientos de una bola activada por la energía de los jugadores; por esa razón la lectura sólo puede ser pensada como proceso. La lectura está insertada en el tiempo.

Pues bien, el texto es un evento en donde ocurren cosas y la más grande de ellas es mi trabajo, la acción que ejerzo sobre la materia dada para transformarla. Produzco excedentes, plusvalía de sentidos, objetos imaginarios, objetos estéticos y acumulo un capital incomparable; la capacidad para percibir, para ampliar mi campo visual, digo mal, para ver lo que no se ve, lo que los ojos no pueden ver, prescindir hasta de mis sentidos, atravesar la densidad del texto para experimentar las simples formas.

Por eso leo, porque es rentable.

Pero ahora me inquieta pensar en los elementos que he dejado a un lado y tengo la impresión de que me he inclinado por más sustantivos que por otras categorías, que no le puse mucha atención a los verbos, que no recapacité en la sintaxis, que no examiné la tendencia del texto a cierto tipo de tropos, etc. etc. ¿Qué selva más intrincada! Me alivia por lo pronto el hecho de que al forjar mis objetos imaginarios, eventualmente y de modo implícito englobé esos factores. Pero no estoy conforme, no estoy segura y me tienta la idea de regresar, de releer el texto y comprobarlo.

Lo releo y me encuentro más cosas, pero la nueva totalidad forjada se integra a la de la primera lectura; de modo que al releer pongo a trabajar el capital acumulado en la lectura anterior y lo aumento. Pienso entonces que la rentabilidad de la lectura se rige entonces por las mismas leyes de la economía, es decir que en el modo de inversión textual la utilidad también es igual a capital, por rédito, por tiempo.

Aprovecho este momento para repasar lo que dije sobre los grados de significar en relación con la imagen literaria y la imagen televisiva.

Resulta entonces que la imagen televisiva parte de una lectura previa; en ella alguien ya ha andado parte del camino y mi lectura es ante todo una relectura. Si yo tomo, por ejemplo, el retrato de María Engracia y lo convierto en un texto fílmico, no aparecerán en ese texto ni el guayabo, ni el guayacán, ni el guiscoyol, ni el elote tierno, ni la pitahaya constituyendo la imagen de esta mujer. De ella aparecerá una imagen que es ya el resultado de una lectura del texto literario. Esto es ganar tiempo pero quemando etapas de proceso y todos sabemos que eso no es posible sin pérdida. ¿En qué consiste la pérdida? A través de su imagen, la televisión ofrece un objeto a nuestra percepción y este objeto percibido está forzosamente empobrecido en relación con la imagen que nos hemos forjado a costa de un esfuerzo de representación. La imagen literaria mantiene facetas múltiples; a pesar de que en determinados momentos de la lectura seleccionemos alguna, las otras facetas siguen insidiosamente en el recuerdo y actúan como plano de fondo hasta que les llegue el momento de actuar. De modo que nuestra representación no fija definitivamente una sola de esas facetas, sino que provee una imagen que representa una síntesis de ellas. La imagen televisiva, por el contrario, como objeto percibido que es, es precisa y por este hecho, más pobre.

\section{Tejiendo el texto de la cultura}

Dice Foucault que un discurso es la emergencia de un concepto. El texto es entonces el objeto que funda el discurso de la lectura en 
nuestros días. Pero agrega Foucault que todo objeto discursivo es tributario de ciertas condiciones, que no emerge por generación espontánea, sino porque en un momento dado históricamente se dan las circunstancias necesarias para producirlo. Por eso, para explicarlo es preciso conocer esas condiciones, es decir, conocer los hechos que hicieron posible su emergencia, saber cuáles fueron sus posibilidades de existencia.

Ya nos hemos referido a ellas, no vamos a volver sobre el asunto. Lo que queremos destacar es cómo ese objeto discursivo teje su propia red de relaciones y prolonga sus ramificaciones reproduciéndose en innumerables conceptos derivados que se concatenan según una gramática que les es propia.

Creo que una de sus derivaciones es esta máquina que tengo en mis manos: la computadora, la lectora más conspicua de nuestros días, nacida de la fuerza extensiva de este nuevo concepto de lectura que nuestra época ha forjado. Pero la relación y la filiación que se establece entre los conceptos de un discurso es $\tan$ íntima y tan densa que la emergencia de las derivaciones se puede revertir en los mismos conceptos de donde proceden; así, el lenguaje y los funcionamientos computacionales se aplican hoy a la teoría del análisis de texto. Ahora los estudiantes hablan, por ejemplo, de los centros programadores del texto y hasta utilizan la computadora para hacer análisis lexicométricos en las obras literarias.
Este parentesco tan cercano entre la lectura y la computación me incita a nuevas reflexiones, inmersos como estamos en un final de siglo que es además final de milenio, sentimiento de conclusión, sensación de final que nos convoca al mismo tiempo a la revisión y a la proyección de nuestro mundo. Pienso entonces en la cultura del texto, nuestra cultu$\mathrm{ra}$, como el umbral del mundo que nos espera y en la computadora como uno de los signos de ese futuro.

Si los vaticinios en tránsito se cumplen, la computadora será el motor del siglo XXI y la era que se avecina será una nueva era alfabética. Entonces el libro, el más antiguo y legítimo reservorio del texto, no está condenado a la extinción, como afirman apocalípticamente algunos, sino que renacerá nuevamente, evolucionado en sus formas, con las facciones que esta otra época le imprima.

\section{Notas}

1. Diccionario de la Real Academia Española. Vigésima edición. Madrid. 1984.

2. Roland Barthes. "De la obra al texto". En Por dónde empezar. Barcelona: Tusquets, 1974.

3. Rafael Angel Herra. El genio de la botella. San José: Ed. Universidad de Costa Rica, 1990.

4. Magón, "La propia". En Historia y Antología de la literatura costarricense de Abelardo Bonilla. San José: Trejos Hnos., 1961. 